\title{
Anti-corruption in the Contemporary Era: Insights from DENG Xiaoping's Anti-corruption and Integrity Upholding Theories---Anti-corruption and Integrity Upholding: "Dogs Catching Mouse" Is Advisable, But the Key Is "Cats Catching Mouse"
}

\author{
Ying Gao, Liang Yao \\ College of Physics and Electronic Information, Yan an University, Yan an, 716000, China. \\ gaoying200777@126.com
}

\begin{abstract}
Keywords: DENG Xiaoping theories, anti-corruption, integrity upholding
Abstract. DENG Xiaoping's anti-corruption and integrity upholding theories are used to analyze the intense "anti-corruption storm" after the 18th CPC National Congress and anti-corruption measures for the future are put forward: "dogs catching mouse" is advisable, but the key is "cats catching mouse”.
\end{abstract}

\section{Introduction}

In the 18th CPC National Congress report, the General Secretary Mr. XI stated the good momentum in CPC Central Committee's continual efforts to combat corruption and uphold integrity and made the most forceful call for us to combat corruption and create a clean political environment. In the 18th CPC National Congress, not only was the viewpoint that corruption will cause fatal damage to the Party expressly stated, the viewpoint that, if the issue of corruption is not addressed, the Party and the country will no longer exist, was also put forward, and the severity and harm of corruption were more thoroughly recognized.

Corruption is a "malignant tumor" of the society, and how to deal with corruption has become a universally difficult issue. With respect to this issue, the 18th CPC National Congress report puts forward the guidelines of persisting in resolving the current problems and eliminating the root causes, adopting a comprehensive approach, imposing punishments and preventing corruption at the same time and laying emphasis on prevention so as to comprehensively promote development of a corruption punishment and prevention system and achieve the goals of incorruption of cadres, the government and politics, thus the goals are more specific. Meanwhile, the 18th CPC National Congress report also said that we need to stick to the anti-corruption and integrity upholding road with Chinese characteristics, adhere to the policy that the Party shall manage itself strictly, improve the Party's self-purification, self-improvement, self-reformation and self-enhancement abilities through stepping up the Party's efforts for improvement of the ideological level, organization structure, work style, incorruption and integrity level and the system, and firmly believe that our ruling party can purify itself. As a matter of fact, the anti-corruption and integrity upholding thoughts put forward in the 18th CPC National Congress are not without sources; instead, they have inherited and innovated the anti-corruption and integrity upholding thoughts of several generations of leaders of the Communist Party of China. The anti-corruption and integrity upholding thoughts put forward by DENG Xiaoping, the chief designer of China's reform and opening-up policy, remain highly instructive for the modern society.

After the 18th CPC National Congress, the new leadership of CPC also talked about "anti-corruption" frequently, and many local governments intensified their anti-corruption efforts to respond to the "anti-corruption trend" from the senior leadership. Within less than 20 days after the end of the 18th CPC National Congress, according to incomplete statistics, nationwide 12 officials, one of whom was a provincial / ministerial-level one, had been investigated by the Commissions for Discipline Inspection due to being reported or being suspected of being involved in violation of various rules, which shows that, in a very long period in the future, anti-corruption and integrity upholding will become a focus of the new leadership. 
The Party and government have always been sticking to the principles of resolutely fighting against and legally punishing corruption, and the 18th CPC National Congress further recognized the harm of corruption, explicitly put forward the new goals of anti-corruption and integrity upholding and demonstrated the Party and government's resolution to combat corruption and uphold integrity. Against such background, drawing upon comrade DENG Xiaoping's anti-corruption and integrity upholding thoughts and further inheriting and innovating the same can help us to further identify the anti-corruption direction and methods. Below I will use comrade DENG Xiaoping's anti-corruption and integrity upholding thoughts to analyze specific anti-corruption and integrity upholding efforts after the 18th CPC National Congress and put forward development countermeasures for combating corruption and upholding integrity in the future.

Within less than 20 days after the end of the 18th CPC National Congress, according to incomplete statistics, nationwide 12 officials were removed from office in succession.

On Nov. 20, after LEI Zhengfu's year 2007 indecent video was spread online, Chongqing Municipal Commission for Discipline Inspection quickly investigated the matter, and within a short period, 71 hours, comrade LEI Zhengfu was removed from the position of Secretary of Beibei District Committee of the CPC and an investigation was initiated.

On Nov. 26, Guangdong Province Discipline Inspection \& Supervision Website released the news that, LU Yingming, the Deputy Head of the Department of Land and Resources of Guangdong Province, was being investigated by the CPC due to serious violations of discipline, which occurred less than one month after LU Yingming was promoted to Deputy Head of the Department of Land and Resources of Guangdong Province from Water Resources Department.

On Nov. 27, Guangdong Province Qingyuan City Discipline Inspection \& Supervision Website released the news that, ZHENG Beiquan, the former Deputy Mayer of Yingde (a city affiliated to Qingyuan City) Government and former Head of the Municipal Public Security Bureau, was being investigated by Qingyuan City Commission for Discipline Inspection due to being suspected of having bent the law for selfish ends and serious economic problems. The cause was that, at the end of September of this year, a thread entitled About 100 Persons Caught after Drug Taking and Trafficking, with Boss Being Younger Brother of Head of Public Security Bureau - Truths about "Mar. 23" Drug Taking and Trafficking Major Case in Yingde City, Guangdong was posted under the names of XIE Longsheng and ZHU Yingzhong, saying that ZHENG Beiquan had acted as a protective umbrella for a gang of drug addicts and traffickers, took advantage of his powers to interfere in XIE Longsheng and ZHU Yingzhong's handling of the case and used harsh words to threaten the police officers many times.

On Nov. 28, Guangdong Province Commission for Discipline Inspection confirmed that, CHEN Hongping, the former Secretary of Jieyang City Committee of the CPC and currently Chairman of Rural Areas \& Agriculture Committee of the Provincial People's Congress, was being investigated by the CPC due to being suspected of serious discipline violation.

On Nov. 30, a Letter of Promise to Divorce written by SHAN Zengde for his mistress became a hit on the Internet. Shandong Province Commission for Discipline Inspection said that the matter stated in the online thread about the Letter of Promise written by SHAN Zengde, Deputy Head of Shandong Provincial Department of Agriculture, for his mistress, had been preliminarily verified. Shandong Province Commission for Discipline Inspection has launched an investigation and the investigation result will be timely published.

From the above, we can see that in our "anti-corruption storm" carried out after the 18th CPC National Congress, surprisingly "online anti-corruption" has played an important role. From the downfall of LEI Zhengfu and SUN Dejiang to many government officials being investigated after real-name whistle-blowing, the masses blew the whistle, then the government authorities launched investigations, and in the end the persons in question were brought to justice. Such internet-based new anti-corruption model has received much attention from and been highly spoken of by most media and the public, but some media and experts put forward different opinions and viewpoints with respect to "online anti-corruption". 
Owing to microblog's fast spread speed, high degree of involvement by the masses, We Media nature, etc., in this platform, once thrown into the complicated and disorderly microblog world, a photo or a video will trigger butterfly effect whose speed, breadth and depth will be amazing, which makes whistle-blowing through microblog viewed as a cutting-edge anti-corruption tool. In the year of 2012, from the downfall of "Watch Uncle" (YANG Dacai) and "seckill” of "LEI Zhengfu”, a lot of media acclaimed microblog, thinking that the age of "anti-corruption through microblog" has come, even viewing microblog as an embodiment of "justice". I think such opinion make a certain amount of sense, as the rise of microblog, a new type of platform, has profoundly changed the way in which common citizens exercise their voting rights and supervision rights, motivated more common people to participate in public affairs and tremendously expanded the channels for supervision on the officials by public opinions. These coincide with the idea of relying upon the masses to combat corruption which was put forward by DENG Xiaoping and the 10th CPC National Congress.

Nevertheless, I think that anti-corruption through microblog also has its drawbacks. First of all, during vigorous anti-corruption through microblog, not all whistle-blowers did it for justice; instead, what are behind a lot of successful online anti-corruption cases are acts done to give vent to anger arising from conflicts of interests or disagreement over distribution of illegal gains, for example, it is said that the indecent video about LEI Zhengfu was made public because the local businessmen wanted to threaten him. Some others even used microblog to maliciously defame and attack them. Let's leave these aside for now and state the "limitations" of anti-corruption through microblog from another perspective, namely microblog's function of spreading information. As a matter of fact, the wide spread of information on microblog depends heavily on the "interests" of the onlookers. Either LEI Zhengfu, who was involved in an indecent video, or the Deputy Head of Shandong Provincial Department of Agriculture, whose "Letter of Promise to Divorce" written for his mistress was made public, among many others, received attention because of the catchy "tidbits" about sex photos, mistresses, expensive watches, etc. Those corruptions involving no eye-catching elements may be neglected by the internet users. Therefore, to a certain degree, anti-corruption through microblog is just like "trying luck". Without something shocking, some microblogs can very easily receive no attention at all, and, as for whether the officials in question can be brought to justice, there are too many uncertainties from online whistle-blowing to internet users paying attention to the matter, to spread by the media and then to authorities' investigations. Therefore a lot of people think that the corrupt officials who hit the "muzzle" and then brought down are just "unlucky" and do not have faith in law enforcement, i.e. they do not believe that "anyone who do illegal acts will surely get caught".

Hence, the new anti-corruption ways that come into being after the 18th CPC National Congress, such as "anti-corruption through microblog" and "online anti-corruption", have further expanded the channels for common citizens to participate and played an active role in anti-corruption and integrity upholding. That's why in future anti-corruption, we need to give full play to the functions of the masses and the internet. For anti-corruption they are outsiders of the system, i.e. as described by an inappropriate idiom, it's like "dogs catching mouse”, but such acts are not only advisable but also must be advocated. The authorities concerned shall immediately investigate into the corruption information on the internet, such as microblog, and timely inform the public of the result.

However, if only such type of anti-corruption model is relied on, anti-corruption and integrity upholding will become accidental and irregular. With the upsurge of online anti-corruption, we need to soberly identify the achievements and situation and keep a rational and constructive attitude towards the defects in institutionalization of anti-corruption. Online anti-corruption can only resolve the current problems, but cannot eliminate the root causes of corruption. We should rely more on the government's discipline inspection and supervision system, seek more for institutionalization of anti-corruption and satisfactorily improve the laws on disclosure of officials' property, transparency of government information, monitoring of exercise of powers, etc. so that the anti-corruption laws and regulations can be fully utilized in law enforcement, which is the inevitable road to anti-corruption. This is also what "the system and the laws are more reliable" among DENG Xiaoping's anti-corruption and integrity upholding thoughts means. To put it using a more common expression, the key is relying on "cats catching mouse”. 


\begin{abstract}
Summary
In conclusion, on the future road to anti-corruption, I hereby put forward such a viewpoint: "dogs catching mouse" is advisable, but the key is "cats catching mouse". To realize such goals, the following needs to be accomplished: first of all, we need to enhance reform of the anti-corruption organs, change their working mechanisms and unclog the anti-corruption channels to make the anti-corruption organs more independent and have greater and more powers; secondly, we need to establish and improve relevant legal systems, such as the property disclosure system, the power restriction system, the power supervision system, etc.; thirdly, we need to bring the basic role of education into full play and improve the anti-corruption and integrity upholding education's effectiveness. Education's influence on a person and even a country and a nationality are far-reaching, thus we need to give full play to the functions of ethics education, enhance cadre education on Party spirit, Party disciplines and national laws as well as anti-corruption trainings and make anti-corruption and integrity upholding education an important part of the theory study by the CPC committees at various levels so that the basic quality of the government officials can be continuously improved and they can truly serve the people whole-heartedly.
\end{abstract}

\title{
References
}

[1] Selected Works of Deng Xiaoping: Volume 3 [M]. Beijing: People’s Press, 1993:379.

[2] Selected Works of Deng Xiaoping: Volume 3 [M]. Beijing: People’s Press, 1993:382.

[3] Selected Works of Deng Xiaoping: Volume 3 [M]. Beijing: People’s Press, 1993:110.

[4] Selected Works of Deng Xiaoping: Volume 3 [M]. Beijing: People’s Press, 1993:142.

[5] Selected Works of Deng Xiaoping: Volume 3 [M]. Beijing: People’s Press, 1993:16. 